\title{
The Ability of implementing Cloud Computing in Higher Education - KRG
}

\author{
Zanyar ali ahmed \\ Information Technology Department, \\ Technical College of Informatics, \\ Sulaimani Polytechnic University, \\ Sulaimani, Iraq \\ zanyar.ahmed@spu.edu.iq
}

\author{
Mazen Ismaeel Ghareb \\ Computer Science Department. \\ College of Science and Technology, \\ University of Human Development \\ Sulaimani,Iraq \\ mazen.ismaeel@uhd.edu.iq
}

\author{
Ako Abubakar Jaafar \\ Computer Science Departmen, \\ College of Science and Technology, \\ University of Human Development \\ Sulaimani,Iraq \\ ako.abubakr@uhd.edu.iq
}

\begin{abstract}
Cloud computing is a new technology. CC is an online service can store and retrieve information, without the requirement for physical access to the files on hard drives. The information is available on a system, server where it can be accessed by clients when it's needed. Lack of the ICT infrastructure of universities of the Kurdistan Regional Government (KRG) can use this new technology, because of economical advantages, enhanced data managements, better maintenance, high performance, improve availability and accessibility therefore achieving an easy maintenance of organizational institutes. The aim of this research is to find the ability and possibility to implement the cloud computing in higher education of the KRG. This research will help the universities to start establishing a cloud computing in their services. A survey has been conducted to evaluate the CC services that have been applied to KRG universities have by using cloud computing services. The results showed that the most of KRG universities are using SaaS. MHE-KRG universities and institutions are confronting many challenges and concerns in term of security, user privacy, lack of integration with current systems, and data and documents ownership.
\end{abstract}

Keywords: Cloud Computing, Challenges, Higher Education, E-learning as a Service, Google cloud computing

\section{INTRODUCTION}

The Higher educations in each society have big responsibilities for developing the country. The cooperation between universities, government and market, specialists and students has demonstrated their commitment to the change of society and the whole world economy [1].

Cloud computing set of hardware and software to human beings via internet. It offers stable, quick, sample, suitable and simultaneous accessibility of belongings at decreased cost via internet to the consumers.

Users can request resources according to their requirements, for instance data storage space, communication, processing and calculation cycles required for their applications [2].

That $\mathrm{CC}$ in Higher Education might provide on instructors Also understudies make it an alluring choice in university situations. The capacity will collaboratively share, edit, process, What more store tremendous sums from claims information have clear provisions inside the
Examine Furthermore instructive communities [7].

\section{Literature review}

Generally the Cloud services consisted of these types:.

-Infrastructure as a Service (IaaS): Products offered by methods for this mode incorporate the remote transport (through the Internet) of a full PC framework (e.g., virtual PCs, servers, storage devices, etc.);

-Platform as a Service (PaaS): should see this cloud computing layer one needs on keeping in mind the accepted computing model where each application mainly hardware, an operating system, a database, middleware, Web servers, Furthermore other programming

-Software as a Service (Saas): Under this layer, applications are delivered through the medium of the world wide web as a service[24].

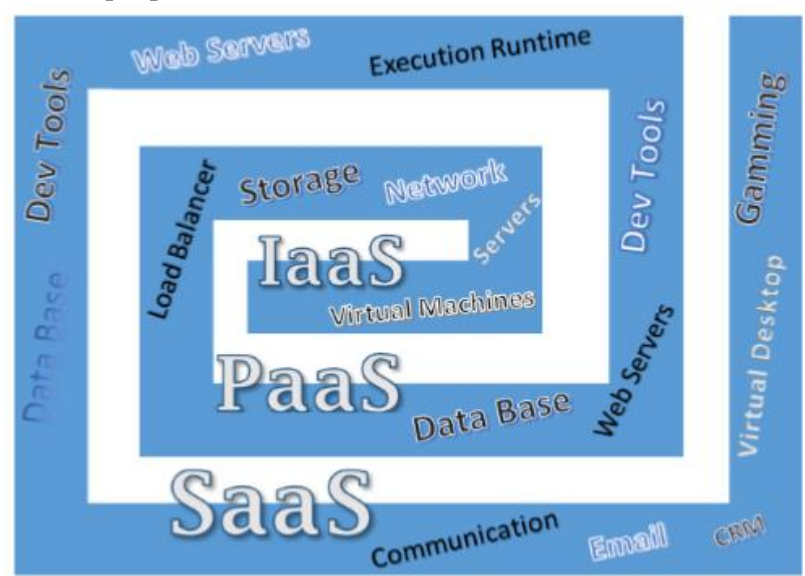

Figure1. Cloud Computing service models[27]

-E-learning as a Service (eLaaS) is a stage that gives an extensive scope of learning and instructing administrations to staff and customers/relates remotely over the web (e-learning). The showing materials are sent to customers/partners by means of the web, an intranet inside the organization or an extranet [28].

Latest "cloud" framework,for instance,"Microsoft" and "Google" are without offering organizations to understudies and staff at enlightening establishments which consolidate email, contact records, timetables, reportedly stockpiling, creating and sharing documents and the ability to make websites [25]. 
The CC in instruction use SaaS Service to public and private universities in the KRG, like "Google App". At that point came Google Docs in 2006 which truly conveyed distributed computing to the cutting edge of open awareness. While 2009 and 2014 saw the greatest number of organizations entering this space [13].

\section{Adoption of cloud computing in Higher Education}

Cloud computing gives a great advantages of users everywhere throughout the fields. It enables clients to get into programming, foundation and stages at whatever time and any place everywhere throughout the world wide web. There are a many research papers that investigate the usage of Cloud Computing in Education Systems. The effect of distributed computing in instruction has picked up attention to numerous analysts and country [3]. According [4] recorded five software products utilizing Software as a service model. By utilizing Saas, huge vendors like Microsoft, IBM, Oracle and amazon offers different instructive programming and applications in less cost. The software that can be utilized by academician and students are Microsoft 365 , amazon, Google Bigquery, and Rackspace Email. While [5] listed out Google Apps and Zoho Office. Moreover [6] recorded six applications in light of the huge organizations and its application, that offers SaaS service models. Investigation of the regular use of CC in Higher Education System such as, Zmanda, Microsoft, IBM, Google, HP and Amanda and Amazon is the organizations. The institutions of Higher Education's must adapt these new technologies of $\mathrm{CC}$ and keep offering their students updated software, good service and high technology in order keep the quality of education in high standard.. [8] Discussed on these six key characteristics as advantage of using cloud computing, which are asset usage, multi occupancy, flexibility, on request prepared cost model, self proving of resources, and online access. [4] Listed 7 points of advantages of utilizing SaaS in CC. These key features are the access of $\mathrm{CC}$ are unlimited, cheaper than other services, no need for installation, usability, no installation spending time, flexible on the quantity of cloud users, easy to learn and use among organization, at last, [11] included five principal points of interest of $\mathrm{CC}$ which are, wide Network, asset pooling, on demand self request fast adaptability and measure services .In higher education cloud the main users are faculty / staff department, students, administrative staff, assessment staff and Admission staff as appeared in Figure 1.

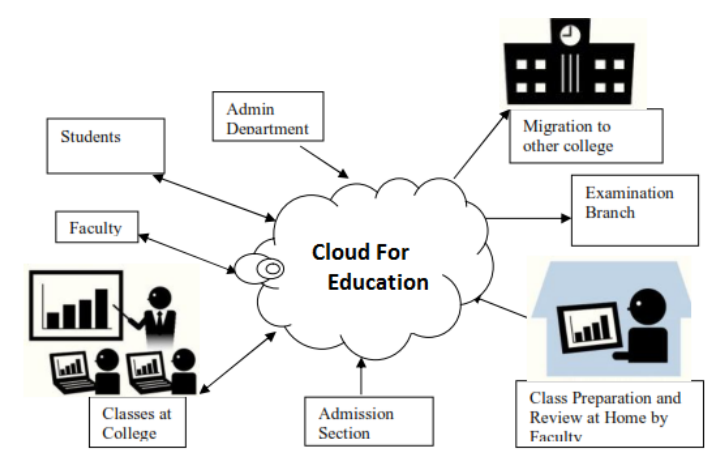

Figure2. Cloud Computing in Higher Education systems [12]

The CC technology had been developed in the education system in a few nations, for example, United Kingdom (UK), USA ,Australia , Lithuania , Pakistan ,Kenya,Kingdom of Saudi Arabia, India and China.

UK had utilized technology of Scantron sheets which allows the students to answer exams or test or quizzes as form of multiple choice questions, which can be access to by both the lectures and students through the $\mathrm{CC}$ technology, which are accurate, quick and can be gotten to any place and at whatever time using the web [12]. UK additionally had it initially Cloud school on systems some of High Schools [13]. Through the usage, the lab situated in the school it will teach the students via provided services of $\mathrm{CC}$.

In the USA some of Online High School uses the cloud applications. These applications have effectively reduced the cost and effort of the administration of the school from pressing, ship, and inventory software installation. A significantly more propelled case of the utilization of distributed computing is the virtual science laboratory keep running by Several Universities in USA. The venture is a helpful exertion keep running by the two advanced education organizations to share their top of the line logical softwares with instructors of secondary school over the Internet to bolster virtual science labs. The Manger of their lab extends, contends that virtual laboratory are similarly as great, if not superior to anything real or physical laboratories, in planning students for current lab examine [15]. Adding more some other educational institutes, for instance, is working with IBM to give $\mathrm{CC}$ applications, figuring force, and storage room to each government school in the USA [16]. Towards the finish of 2009 IBM announced the arrival of its Cloud Academy which it portrays as, a online service for instructors, analysts and IT workforce at advance instructive organizations to seek after distributing computing activities, create abilities and offer accepted procedures for lessening working expenses while enhancing quality and access to training [16].

The Ministirs of educations have begun distributing educational contain on iTunes, which is deliver several Apple Store, enabling instructors to share materials in October 2009.. While the ministry of educational substance is composed primarily for the expert improvement of educators, the CEnet's commitments are 
chiefly classroom-situated. Despite the fact that iTunes $\mathrm{U}$ was initially intended for colleges and other tertiary organizations it now actively caters for secondary schools [19]. The CC delivers computing and storage assets to its students. It acts as a service on request approach. Distributed computing is another plan of action wrapped around new technology like virtualization, SaaS and broadband web. Late interests offered new applications software and mobile adaptability with higher computing parameters in Higher education [20].

In Lithuania has been executing cloud technology in their education process in a few universities. Focal piece of the CC infrastructure has been established.. The framework comprises of many parts like University email framework, managements of Academics System, Library data frameworks, e-learning frameworks (like Moodle), and so forth. The latest administrations IT branch gives Microsoft Live@Edu Cloud benefit. Students and lectures can utilize university email benefit (running on Microsoft Exchange). This will support educators and students to learn and cooperate [21]. Both instructors and students can likewise utilize different administrations accessible in Live@Edu, for example, 25GB free storage, information synchronization, texting and all Microsoft Office applications online in CC.

In Pakistan, lack of halls, lecture, laboratory, interactive media, skilled and expert instructors and technological based belonging are aggravating the dissemination of valuable training. Selection of CC in education condition can solve these challenges by using $\mathrm{CC}$ in Education system. By and by Gmail, Google sites, yahoo and Hotmail are playing an imperative part in education system [22].

In Kenya proposed the huge Open Online cloud classes for e-Learning in several schools. The cloud offers the instructive web platform framework for educations. The proposed solution resolves various issues; for example availability of lecturer lectures, students' exam results ,exams, evaluation and administration of eLearning [23].

In India a cloud based solution has been used, it utilized as a part of the education sector. Their Cloud empowers the institutions for all students' related records and portfolio details to be stored in central database [6].

$\mathrm{CC}$ has been giving upgraded adequacy, usefulness, efficiency, reliability and cost productive advantages in the eLearning training arrangement of Kingdom of Saudi Arabia [24].

In addition, in Chinese Google universities has started to set up academic cloud by giving scholarly association dares to huge scale information preparing sessions, for example, community oriented activity, which gets the Cloud administrations from Google and deals with these assets by giving laboratory facility [26].

\section{State of Cloud Computing in Higher Education-KRG}

The higher education in KRG is organized based on KRG regulation and rules under the Ministry of Higher Education and Scientific Research in KRG (MHEKRG). In The last decades the number of enrolled students with a number of public and private university dramatically increased in KRG [9]. According to [10] currently there are 18 public and 24 private universities and institutes in the KRG. However the MHE-KRG is trying to reform the process of higher education in the KRG. The reform strongly starts with establishing the Quality Assurance Unit (QA). QA is responsible for monitoring and evaluating students' learning process and teachers' performance. In addition National University Ranking (NUR) has been introduced by MHE-KRG to evaluate national universities in KRG based on various criteria. MHE_KRG is tending to boost the process of higher education to meet sustainable development requirements in KRG [14].

\section{Methodology}

KRG universities and higher education institutions are willing to use up to date technologies in the education process and teaching methodologies. Although using modern Information and Communication Technologies (ICT) are the cornerstone of modern education system, but MHE_KRG suffers from lack of ICT infrastructure in KRG [17,18]. Also, establishing ICT infrastructure for universities needs extensive time and efforts. Using the unstructured educational system and technologies is another problem in MHE-KRG.

In order to tackle these problems in the higher education institution and universities in the KRG are trying to increase their awareness toward using cloud computing to get advantages in providing better educational environment. Therefore, we conducted a survey in KRG universities to determine the scale of using cloud computing in MHE-KRG. In the survey 222 academic staffs and students from 14 universities participated in the survey. We have designed the questions regarding the needs to apply CC in higher education in the KRG. Find where it has been used. What are the drawback of applying CC .Table 1 below shows the survey questions:

\begin{tabular}{|l|l|}
\hline No. & Questions \\
\hline 1 & Do you have any knowledge about cloud computing? \\
\hline 2 & Is your university use any cloud computing services? \\
\hline 3 & Which cloud solutions have been adopted in your university? \\
\hline 4 & Do satisfy with current cloud solution in your university? \\
\hline 5 & $\begin{array}{l}\text { Is your university, train you about using cloud computing } \\
\text { services? }\end{array}$ \\
\hline 6 & $\begin{array}{l}\text { In your opinion, what are the advantages of using cloud in } \\
\text { your university? }\end{array}$ \\
\hline 7 & $\begin{array}{l}\text { What are the risks that may confront your university when } \\
\text { they use the cloud? }\end{array}$ \\
\hline 8 & $\begin{array}{l}\text { What were or are the greatest barriers for adoption of cloud } \\
\text { computing in your organization? }\end{array}$ \\
\hline
\end{tabular}

\section{Results}

The main questions of the survey have analyzed regarding the implementing $\mathrm{CC}$ in $\mathrm{KRG}$ with standard rules and regulation, adding to that to show the drawbacks of immolating it and shows best way possible to make it easy to implement.

As shown in figure 2, 52.3\% of universities use cloud services and most of these clouds are available, public clouds from companies like Google, Microsoft, Dropbox and etc. 


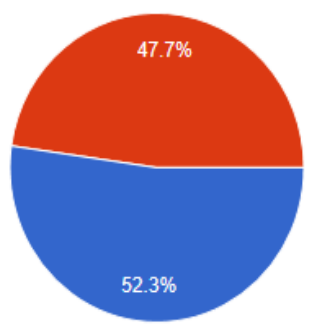

Figure 3:Using Cloud Computing Rate in MHE-KRG

The advantages of using cloud such as availability, cost saving, and outsourcing because of poor home development are the main reasons to implement cloud computing. Figure 3 shows that $57.2 \%$ of users use cloud computing because of availability. Cost saving is the second highest reason to use cloud computing in KRG universities. In addition, $28.8 \%$ of users believe that other advantages of using cloud in MHE-KRG is outsource development and maintenance.

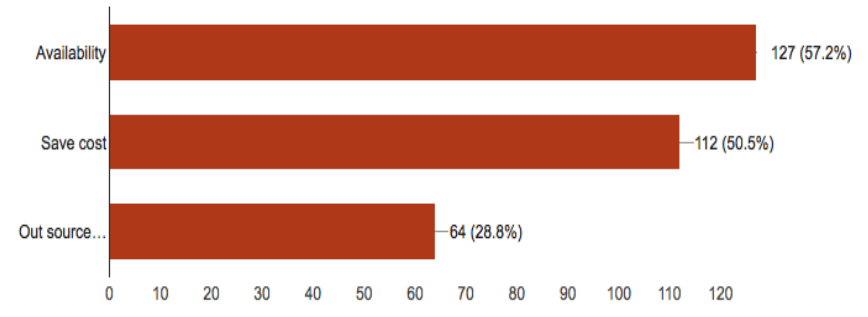

Figure 4: Benefits of CC in MHE-KRG

Various implementations of cloud services in MHEKRG has been considered for different purposes. As the survey depicted the SaaS is the most used cloud services in MHE-KRG University. However, some universities implement a Google cloud platform to perform their activities, such as Google site which part of (PaaS). According to the survey public cloud has been used for various purposes. The sectors that use cloud computing are instituted management, class management, research, teaching, human resource, communication, and document management. Google cloud has the broad usage in MHE-KRG sectors. Figure 4 and Figure 5 shows the implemented cloud service with their purposes as well as the using rate of different cloud services by academic staffs and students.

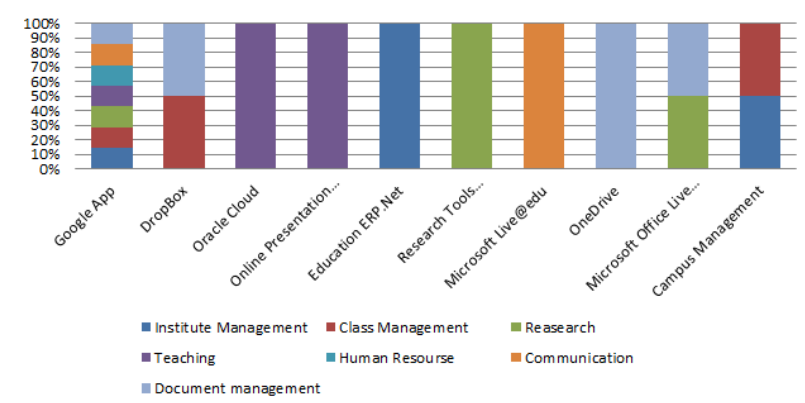

Figure 5: The Implemented Cloud in MHE-KRG and Their Purposes

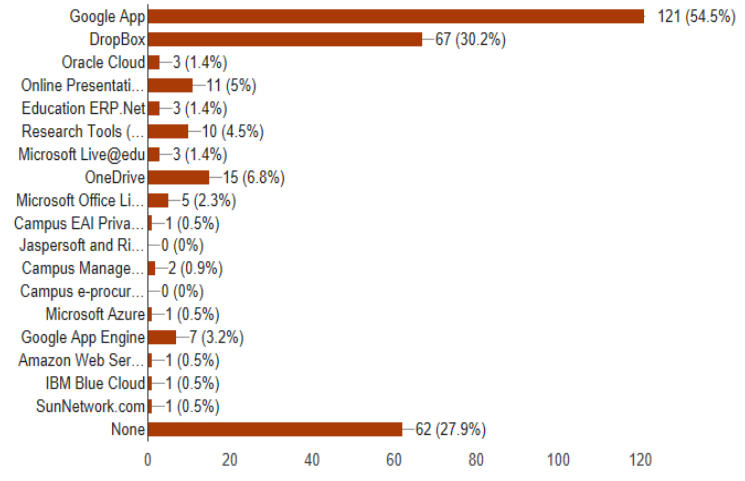

Figure 6: Implementation Rate of Cloud Computing

\section{Discussion}

Despite the importance role of cloud computing in higher education, implementation of cloud computing in MHE_KRG confronts many concerns and challenges. The survey depicted security and privacy has the highest concerns in a cloud computing. The security concern comes from sharing properties which lead them to be uncertain about pushing critical information.

The information ownership and inability to control the data and document is another concern by organizations and users. In contrast to home developed system the current cloud solution in MHE-KRG does not provide a well customization and personalization.

Although the implemented cloud solution in MHE-KRG provides the useful infrastructure, tools, and platform, but the lack of integration with the home developed system is one of the drawbacks of it. This drawback leads to increased data redundancy and poor data management. In addition performance and service availability is another concern of users in MHE-KRG university. Since, they believe that there isn't any guarantees from outside vendors to provide continuous availability and high performance. The concern rate of users in MHE-KRG showed in figure 6. Furthermore, one of the challenges that face universities is rising the education level of users since the survey shows that many academic staff or students use at least one cloud services daily while they don't have any knowledge about cloud computing and how they have to deal with it.

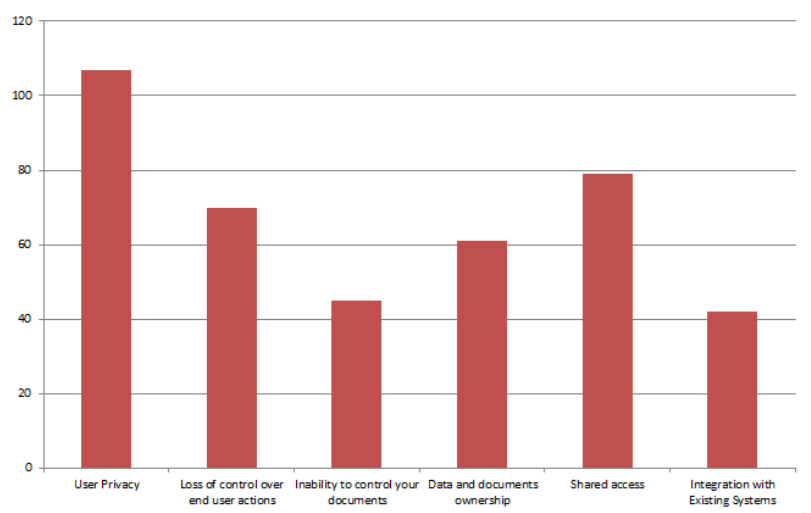

Figure 7: Cloud Computing Challenges and Concerns in Higher Education KRG 


\section{CONCLUSION}

Cloud computing is a new method for developing a significant option in today's education process. MHEKRG University and institution have the chance to rapidly and economically get to different application platforms. The aim of this research was to investigate the usage of cloud computing in higher education in the KRG. The paper gave an introduction of the service that have been used in higher education, such as Infrastructure as a Service Iaa, Platform as a Service PaaS, and Software as a Service SaaS. The state of cloud computing and their service in higher education has been clarified. In addition, the state of cloud computing in several countries such as USA, UK, Australia, China, Kenya has been examined. Furthermore a survey has been conducted to show cloud computing implementation status and applicability in MHE-KRG. The results showed that the most of KRG university is using SaaS. Furthermore, The researchers showed that the main reasons to use cloud computing in MHE-KRG are lack of ICT infrastructure in the KRG, Service availability, and outsourcing. Moreover MHE-KRG universities and institutions confronts many challenges and concerns in term of security, user privacy, lack of integration with current systems, and data and documents ownership. Finally, we believe that to reduce the drawbacks of public cloud and get the advantages of cloud computing higher education institution and universities in KRG has to change their strategies from using public clouds to use their owned clouds.

\section{ACKNOWLEDGMENTS}

We would like to thank all the universities of Kurdistan region government for answering our survey, special thanks to University of Human Development and Sulaimani Polytechnic University for their continues support.

\section{REFERENCE}

[1] V. H. Pardeshi, "Cloud Computing for Higher Education Institutes: Architecture, Strategy and Recommendations for Effective Adaptation," Procedia Economics and Finance, vol. 11, pp. 589599, 2014.

[2] S. Riaz and J. Muhammad, "An evaluation of public cloud adoption for higher education: A case study from Pakistan," 2015 International Symposium on Mathematical Sciences and Computing Research (iSMSC), 2015.

[3] M. A. H. Masud, J. Yong and X. Huang, "Cloud Computing for Higher Education: A roadmap," Proceedings of the 2012 IEEE 16th International Conference on Computer Supported Cooperative Work in Design (CSCWD), Wuhan, 2012, pp. 552557.

[4] A. O. Akande and J. P. Van Belle, "Cloud computing in higher education: A snapshot of software as a service," 2014 IEEE 6th International Conference on Adaptive Science \& Technology (ICAST), Ota, 2014, pp. 1-5.

[5] H. Zhao, Y. Wang, and L. Yang, "Research on distance education based on cloud computing,"
2011 6th International Conference on Pervasive Computing and Applications, 2011.

[6] F. A. Alshuwaier, A. A. Alshwaier and A. M. Areshey, "Applications of cloud computing in education," 2012 8th International Conference on Computing and Networking Technology (INC, ICCIS and ICMIC), Gueongju, 2012, pp. 26-33.

[7] S. Ashtari and A. Eydgahi, "Student Perceptions of Cloud Computing Effectiveness in Higher Education," 2015 IEEE 18th International Conference on Computational Science and Engineering, Porto, 2015, pp. 184-191.

[8] H. P. Breivold and I. Crnkovic, "Cloud Computing education strategies," 2014 IEEE 27th Conference on Software Engineering Education and Training (CSEE\&T), Klagenfurt, 2014, pp. 29-38.

[9] A. Ahmad and M. Shah, "The rise of private higher education in Kurdistan," A Global Perspective on Private Higher Education, pp. 219-228, 2016.

[10] "Quality Assurance in Higher Education in the Kurdistan region," Ministry of Higher Education and Scientific Research, 20-Feb-2015. [Online]. Available: http://newsite.mhe-krg.org/node/3367. [Accessed: 2017].

[11] M. M. Alabbadi, "Cloud computing for education and learning: Education and learning as a service (ELaaS)," 2011 14th International Conference on Interactive Collaborative Learning, 2011.

[12] N. Alsaeed and M. Saleh, "Towards Cloud Computing Services for Higher Educational Institutions: Concepts \& Literature Review," 2015 International Conference on Cloud Computing (ICCC), 2015.

[13] "THE USE OF CLOUD COMPUTING IN HIGHER EDUCATION: REALITY ..." [Online]. Available:

https://www.bing.com/cr?IG=C59807DFBB6D498 A9B9AADA98D0D05FA\&CID=3BE03D101B456 71D2EC437C01A43667A\&rd=1\&h=zC_Na5bqnV QTXnHcLUJB4SESMAAu8ggdyWOA6WKHD4

$\mathrm{Y} \& \mathrm{v}=1 \& \mathrm{r}=\mathrm{https} \% 3 \mathrm{a} \% 2 \mathrm{f} \% 2 \mathrm{fwww}$.westeastinstitut e.com $\% 2$ fwpcontent $\% 2$ fuploads $\% 2 \mathrm{f} 2015 \% 2 \mathrm{f} 07 \% 2 \mathrm{fIbraheem}-$ Alzahrani.pdf\&p=DevEx,5062.1. [Accessed: 09May-2017].

[14] "Why NUR," NUR-KRG. [Online]. Available: http://www.nur-krg.net/why-nur. [Accessed: 02May-2017].

[15] "Post navigation," Wired Campus New Project Promotes Virtual Science Labs Despite Skepticism Comments. [Online]. Available: http://www.chronicle.com/blogs/wiredcampus/new -project-promotes-virtual-science-labs-despiteskepticism/9162. [Accessed: 25-Apr-2017]..

[16] P. K. Bv, S. Kommareddy, and U. R. N, "Effective Ways Cloud Computing Can Contribute to Education Success," Advanced Computing: An International Journal, vol. 4, no. 4, pp. 17-32, 2013..

[17] S. M. Shareef and J. Arreymbi, "E-Government Initiatives in Kurdistan Region of Iraq," Advances in Electronic Government, Digital Divide, and Regional Development E-Government Implementation and Practice in Developing 
Countries, pp. 1-33.

[18] A. Jaffar, M. I. Ghareb, and K. K. Sharif, "The Challenges of Implementing E-Commerce in Kurdistan of Iraq," Journal of University of Human Development, vol. 2, no. 3, pp. 528-533, Jan. 2016.

[19] "Australian School Holidays on the App Store itunes.apple.com." [Online]. Available: https://www.bing.com/cr?IG=C71789F028A34544 B707B863A17FD7E8\&CID=2359306C85386A1D 18AB3ABC843E6B76\&rd=1\&h=Z747GO0Bpmx bhtcCpWw9PAQEF1zrbH7jlzTCs8xKcM\&v=1\&r $=$ https $\% 3 \mathrm{a} \% 2 \mathrm{f} \% 2$ fitunes.apple.com $\% 2 \mathrm{fau} \% 2 \mathrm{fapp}$ $\% 2$ faustralian-schoolholidays\%2fid979479932\&p=DevEx,5065.1. [Accessed: 01-Jun-2017]..

[20] T. Ercan, "Effective use of cloud computing in educational institutions," Procedia - Social and Behavioral Sciences, vol. 2, no. 2, pp. 938-942, 2010.

[21] "Application of Cloud Computing at KTU: MS Live@Edu Case." [Online]. Available: http://www.bing.com/cr?IG=FCB5BA2475B847 BBBBAFF9992E9B9C11\&CID=2565CB7FFEB 366D905F3C1AFFFB 56785\&rd =1 \&h=hAV0A6 04TbkGuPHxf3FqsiL0L3dHPnHsCY4spNLU7E $\mathrm{s} \& \mathrm{v}=1 \& \mathrm{r}=\mathrm{http} \% 3 \mathrm{a} \% 2 \mathrm{f} \% 2 \mathrm{ffiles}$.eric.ed.gov $\% 2 \mathrm{ff}$ ulltext\%2fEJ1064299.pdf\&p=DevEx,5063.1. [Accessed: 31-May-2017].

[22] S. Riaz and J. Muhammad, "An evaluation of public cloud adoption for higher education: A case study from Pakistan," 2015 International Symposium on Mathematical Sciences and Computing Research (iSMSC), 2015.

[23] "A Kenyan Cloud School. Massive Open Online \& Ongoing ..." [Online]. Available: http://www.bing.com/cr?IG=80A7D22944F34D B48BD8139FBDF3DD40\&CID=1083643F75FF 699E13386EEF74F968CF\&rd=1\&h=UAwr0W XUX3qnwnWF_wT7zGL82_9-

kMQOisrWi9lrYNQ\&v=1\&r=http $\% 3 \mathrm{a} \% 2 \mathrm{f} \% 2 \mathrm{fo}$ penpraxis.org\%2findex.php $\% 2 \mathrm{fOpenPraxis} \% 2 \mathrm{fa}$ rticle\%2fview\%2f86\&p=DevEx,5064.1.

[Accessed: Sep-2017].

[24] N. Sultan, "Cloud computing for education: A new dawn?," International Journal of Information Management, vol. 30, no. 2, pp. 109-116, 2010.

[25] T. Ercan, "Effective use of cloud computing in educational institutions," Procedia - Social and Behavioral Sciences, vol. 2, no. 2, pp. 938-942, 2010.

[26] C. S. Chang, T. S. Chen and H. L. Hsu, "The Implications of Learning Cloud for Education: From the Perspectives of Learners," 2012 IEEE Seventh International Conference on Wireless, Mobile and Ubiquitous Technology in Education, Takamatsu, 2012, pp. 157-161.

[27] K. H., F. M., M. R., and H. Fajraoui, "Cloud Computing Security Challenges in Higher Educational Institutions - A Survey," International Journal of Computer Applications, vol. 161, no. 6, pp. 22-29, 2017."
[28] "E-learning as a Service (eLaaS)," SingularLogic. [Online]. Available: http://portal.singularlogic.eu/en/service/2385/elearning-service-elaas. [Accessed: 23-Apr-2017]. 